\title{
Outcome of Extracorporeal Shock Wave Lithotripsy in Western Region of Nepal
}

\author{
Ghimire $P^{1 *}$ Yogi $N,{ }^{1}$ Acharya $G B^{1}$
}

${ }^{1}$ Department of Surgery, Manipal Teaching Hospital, Pokhara, Nepal

\author{
*Corresponding Author: \\ Dr. Pradeep Ghimire, MS, FRCS (Ed) \\ Department of Surgery \\ Manipal Teaching Hospital, Pokhara, Nepal \\ Email: pradeepg757@hotmail.com

\section{Citation} \\ Ghimire $p$, Yogi N, Acharya GB. Outcome of Extracorporeal \\ Shock wave Lithotripsy in Western region of Nepal. Nepal \\ Journal of Medical Sciences. 2012; 1(1): 3-6.
}

\begin{abstract}
Background: Extracorporeal shock wave lithotripsy (ESWL) is an effective non-invasive method for management of urinary tract stones. It was introduced for the first time in Pokhara 1 year back. This study aims to study the efficacy of ESWL in removal of renal and ureteric calculus in relation to the stone size and location and potential adverse effect of the procedure.
\end{abstract}

Methods: It is a prospective observational study carried out in 112 cases undergoing elective ESWL for solitary urolithiasis during a period of 1 year (August 2010- August 2011). Number of sessions required for successful fragmentation and clearance of stones were studied according to their size and position along with the complications encountered.

Results: The success rate of ESWL was found to be $91.1 \%$ for solitary urolithiasis. The mean number of sessions required for success was found to increase according to increase in size of the stones whereas it was almost similar for various locations. Complications were encountered in $25 \%$ of cases.

Conclusion: Stone size was found to be the most important predictor in successful outcome of ESWL and the procedure is quite favorable for stones less than $20 \mathrm{~mm}$.

Keywords: ESWL; renal stones; ureteric stones

\section{Background:}

Extracorporeal Shock wave Lithotripsy (ESWL) was first introduced by Chaussy and his co-workers in 1980 and was approved by FDA in $1984 .^{1,2}$ Since then ESWL dramatically changed the management of renal and ureteric calculus disease. Now ESWL represents the first line therapy for the majority of urinary tract calculi. It is a simple and safe technique in which renal and ureteric calculi are pulverized into small fragments by shockwaves and then allowed to pass spontaneously in small fragments along with urine. ESWL is a non-invasive procedure and need lesser or no anesthesia in comparison to other procedures.
ESWL was first introduced in Nepal in BirendraArmyHospital in $1990 .^{2}$ Later on it was also introduced in other centers in and outside Kathmandu valley. In Pokhara, ESWL was first introduced in Pokhara Kidney Stone Centre in 2010 as a collective initiative of various surgeons working at various hospitals in the city. Later it was also introduced in the same year in Gandaki Medical College, Pokhara, Nepal.

The Purpose of this study was to assess the efficacy of ESWL in removal of renal and ureteric calculus in relation to the stone size and location, factors that may affect the outcome and potential adverse effect of the procedure. 


\section{Methods:}

This is a prospective observational study performed in Pokhara Kidney Stone Centre and Manipal Teaching Hospital in 112 cases undergoing elective ESWL for solitary renal stones, stones in the Pelvi-ureteric junction, ureter and vesico-ureteric junction from August 2010 to August 2011. Cases with multiple calculi and calculus in the mid-ureter region were excluded from the study. All patients underwent $\mathrm{X}$-ray of kidney, ureter and bladder (KUB) for visualization of stones. IVU (Intravenous Urography) and USG-KUB was ordered according to the individual need. The size and position were confirmed by a consultant radiologist.

All patients were treated with Allenger's UROLITH+ ESWL Machine targeted under C-Arm Image Intensifier. All patients were given intravenous antibiotic (Gentamycin) and intramuscular diclofenac half an hour before the procedure. After the session patient were given antibiotics and analgesics for 5 days. Patient were observed in the centre for one hour for any immediate complications and then at $7^{\text {th }}$ day with X-ray KUB for clearance of the stone and residual fragments. Follow up was continued for next 4 weeks till complete clearance of the stone or failure to disintegrate. In case of failure to disintegrate, patients were subjected for repeat session of ESWL. The gap between two sessions was 1 month and in case no fragmentation was seen even on multiple sessions, patients were advised for other surgical remedies and were excluded from the study.

Informed consent was taken from all the patients and any patients not willing for repeat sessions of ESWL on failure of disintegration at any sessions, despite the treating surgeon's advice, were also excluded from the study. Data was collected on location and size of the stones and was compared with sessions of ESWL required for successful fragmentation of the stones as outcome measures. One Way ANOVA was used to compare means of various variables of location and size. Statistical analysis was done using SPSS 11.5 software.

\section{Results:}

Over a period of 1 year, we had 123 cases of urolithiasis undergoing elective ESWL out of which 13 cases had failed to disintegrate completely. Such patients were advised to abandon ESWL and go for other surgical procedures either open surgery, PCNL (Per-cutaneous Nephrolithotomy) or endourological procedure and were excluded from the study. Thus, there were altogether 112 cases included in this study. Of the 112 cases, $61(54.5 \%)$ had stones on the left side and $51(45.5 \%)$ had stones at the right side. The mean age of the patients was 36.09 years ranging from 16 to 89 . There were 69 males and 43 females with male to female ratio as 1.6:1. Table 1 shows the age distribution of the patients undergoing ESWL.
Table 1: Age distribution of the patients undergoing ESWL for urinary tract stones

\begin{tabular}{lcc}
\hline Age Interval (Years) & $\begin{array}{c}\text { Number of } \\
\text { Patients }\end{array}$ & Percentage \\
\hline $10-20$ & 9 & $7.5 \%$ \\
$21-30$ & 40 & $33.3 \%$ \\
$31-40$ & 34 & $28.3 \%$ \\
$41-50$ & 15 & $12.5 \%$ \\
$51-60$ & 7 & $5.8 \%$ \\
$61-70$ & 3 & $2.5 \%$ \\
$71-80$ & 2 & $1.6 \%$ \\
$81-90$ & 2 & $1.6 \%$ \\
\hline
\end{tabular}

Majority of the patients undergoing ESWL had stones in the kidney (41\%). Similarly, 37.6\% had stones in the ureter, $18.8 \%$ in the PUJ and $2.7 \%$ in the VUJ.

Majority of the stones subjected for ESWL were less than 10 $\mathrm{mm}(54.4 \%)$. Similarly, $41.1 \%$ of the stones were $10.1-20$ $\mathrm{mm}$ of size, $4.4 \%$ were more than $20 \mathrm{~mm}$ of size. The stones subjected to ESWL ranged from $4.6 \mathrm{~mm}$ to $32 \mathrm{~mm}$ in its greatest diameter.

The number of sessions required for complete fragmentation varied from single to four sessions. Majority of the cases (76.7\%) required single sessions whereas $17.8 \%$ required two sessions. Three patients $(2.6 \%)$ each required three and four sessions respectively for complete fragmentation.

When observed according to various site in urinary tract, the mean number of sessions required for complete fragmentation of the stones were almost similar $(1-1.71, \mathrm{~F}=$ 1.34, $\mathrm{P}=0.26$ ) (Table 2).

Table 2: Number of sessions required for successful fragmentation of stones according to the site

\begin{tabular}{lccccc}
\hline \multicolumn{1}{c}{ Site } & $\begin{array}{c}\text { No. } \\
\text { of } \\
\text { cases }\end{array}$ & $\begin{array}{c}\text { No. of } \\
\text { sessions } \\
\text { (Mean) }\end{array}$ & $\begin{array}{c}\text { Std } \\
\text { Deviation }\end{array}$ & F & $\begin{array}{c}\text { P } \\
\text { value }\end{array}$ \\
\hline Upper Pole & 12 & 1.42 & 0.51 & & \\
Mid Pole & 23 & 1.39 & 0.72 & & \\
Lower Pole & 11 & 1.27 & 0.65 & & \\
$\begin{array}{l}\text { Upper Ureter } \\
\text { Lower Ureter }\end{array}$ & 75 & 1.11 & 0.32 & 1.34 & 0.26 \\
$\begin{array}{l}\text { Pelvi-Ureteric } \\
\text { Junction }\end{array}$ & 21 & 1.43 & 0.93 & & \\
$\begin{array}{l}\text { Vesico-Ureteric } \\
\text { Junction }\end{array}$ & 3 & 1 & 0 & & \\
\hline
\end{tabular}


Similarly, when analyzed according to the various size, stones less than $10 \mathrm{~mm}$ required 1.18 mean numbers of sessions whereas those between $10.1-20 \mathrm{~mm}$ required 1.26 mean sessions and those more than $20 \mathrm{~mm}$ required almost 3.4 mean number of sessions for complete fragmentation ( $\mathrm{F}=50.24, \mathrm{P}=<0.0001$ ) (Table 3).

\section{Table 3: Number of sessions required for successful fragmentation of stones according to their size}

\begin{tabular}{cccccc}
\hline Size & $\begin{array}{c}\text { No. of } \\
\text { cases }\end{array}$ & $\begin{array}{c}\text { No. of } \\
\text { Sessions } \\
\text { (Mean) }\end{array}$ & $\begin{array}{c}\text { Std } \\
\text { Deviation }\end{array}$ & F & P value \\
\hline $0-10 \mathrm{~mm}$ & 61 & 1.18 & 0.39 & & \\
$10.1-20 \mathrm{~mm}$ & 46 & 1.26 & 0.53 & 50.24 & $<0.0001^{*}$ \\
$>20 \mathrm{~mm}$ & 5 & 3.40 & 0.89 & & \\
\hline
\end{tabular}

* Significant

Complications were seen in $28(25 \%)$ cases in our series. Urinary tract infection was seen in $14(12.5 \%)$ cases, ureteric colic in $11(9.8 \%)$ and flank pain with bruise in $6(5.3 \%)$ of cases. None of the cases required any active surgical interventions or hospitalization.

\section{Discussion:}

Before the advent of ESWL and other minimal invasive procedures like ureterorenoscopy and PCNL, open surgery represented the treatment of choice for most renal and ureteric stones. At present era ESWL has been established as the treatment of choice for most of the renal and ureteric calculi due to its noninvasive character, favorable clinical outcome, low complication rate and only a few absolute contraindications (e.g., pregnancy or aortic aneurysms). ${ }^{3}$ However, not all kidney stones are amenable to treatment by ESWL. The success rate of ESWL depends upon various factors like stone size and burden, stone density and composition, location of the stone, renal morphology, congenital anomalies etc. ${ }^{4,5}$ Therefore it is very important to estimate the probability of stone clearance for each individual so as to determine who will experience maximum benefit from ESWL.

In our study we had included and studied various aspects of only those cases that had completed ESWL successfully. There were also 11 cases that were refractory to ESWL and required some form of surgical procedures. Thus the success rate in our series was $91.1 \%$. No other form of ancillary procedures like DJ stenting was required in our series. This could be because there were only 5 cases of stones which was more than $20 \mathrm{~mm}$ and that we had excluded multiple stones, stones in the mid ureter and completely refractory stones which has less chances of disintegration with ESWL. Various studies have reported success rate between $78-86.7 \%$ for renal and $84.2-88.7 \%$ for ureteric stones ${ }^{4-7}$ A recent study in Katmandu suggested $96 \%$ success for solitary stones at 6 weeks which is almost comparable to our result. ${ }^{8}$

In our study, Size of the stone was one of the most important factors determining success of ESWL. The mean number of sessions required for successful fragmentation of the stones increased with increase in size. Stones less than $10 \mathrm{~mm}$ required 1.18 mean sessions, $10.1-20 \mathrm{~mm}$ stones required 1.26 mean sessions and stones more than $20 \mathrm{~mm}$ required 3.4 mean sessions for successful fragmentation $(\mathrm{P}<0.001)$. Lingeman et al described size of the stone as one of the most important factor determining success of ESWL. ${ }^{9}$ Newman D et al in their series of 1910 cases found than success rate was $80 \%$ with $0-10 \mathrm{~mm}$ stones whereas it declined to $60 \%$ with size of the stone greater than $30 \mathrm{~mm} .{ }^{10}$ Lalaket al. in their series of 500 cases reported that overall stone-free rate was $76 \%, 66 \%$ and $47 \%$ for stones of size $<10 \mathrm{~mm}, 10-20 \mathrm{~mm}$ and $>20 \mathrm{~mm}$ respectively. ${ }^{11}$ Similarly Abdel-Khalek et al reported stone free rate as $89.7 \%$ for stones $<15 \mathrm{~mm}$ and $78 \%$ for stones $>15 \mathrm{~mm}(\mathrm{p}<0.0001) .{ }^{5}$ All these authors were of common opinion that size of th0e stone was one of the most important predictive factor for successful outcome of ESWL.

Location of stone is also very important point to consider while treating a patient with urinary stone disease. For renal stones studies suggest that lower pole has got lesser rates of clearance than upper and mid pole. Although, the disintegration rate of lower calyx stones does not differ much than that of stones in other localizations, the clearance of the fragments is not as similar due to the unfavorable spatial anatomy of the lower pole collectingsystem. ${ }^{12}$ Preminger GM et al in their article mention that clearance rate for ureteric stone located at upper, mid and distal ureter were $82 \%, 73 \%$ and $74 \%$ respectively. ${ }^{13}$ Delakas etal. declared distal ureteric stones and stones $>10 \mathrm{~mm}$ to be the strongest independent predictors of failure of ESWL in ureteric stones. ${ }^{14}$ In our series we found not much difference in the mean number of sessions between the various location of urinary tract for complete fragmentation and clearance of stones. The mean number of sessions required ranged from 1 in VUJ and 1.71 in lower ureter.

Altogether $28(25 \%)$ cases had complications in our series and not a single incidence of any serious complications was recorded. Urinary tract infection was seen in 14 (12.5\%) cases, ureteric colic in $11(9.8 \%)$ and flank pain with bruise in $6(5.3 \%)$ of cases. All cases were managed conservatively. Various complications have been reported after ESWL in many series including, UTI and urosepsis, mild and frank hematuria, flank pain and bruises, anuria, steinstrasse etc. 
Steinstrasse is acolumn of stone fragments within the ureter that may cause partial or complete obstruction after ESWL and is usually seen in cases of higher stone load. ${ }^{15,16}$ Complication rates are seen less with newer generation lithotripters. ${ }^{17}$

\section{Conclusion:}

ESWL is a safe option for treatment of urinary tract stones. The overall success rate of ESWL in our series was $91.1 \%$. The overall complication rate was $25 \%$. More than $20 \mathrm{~mm}$ stones required higher sessions for complete fragmentation and clearance of stones ( 3.4 sessions) in comparison to stone of 0-10 mm (1.18) and that of 10.1-20 mm (1.26). Almost similar mean number of sessions $(1-1.71)$ was required for stones at all location for complete fragmentation and clearance. Thus, stone size was found to be the most important predictor in successful outcome of ESWL and the procedure is quite favorable for stones less than $20 \mathrm{~mm}$.

\section{References:}

1. Chaussy C, Brendal W, Schmiedt E. Extracorporeally induced destruction of kidney stones by shockwaves. Lancet 1980;2:1265-8.

2. Nagendra BKC, Sharma U. Comparative study in extracorporeal shock wave lithotripsy with and without the use of local anaesthetic (Lidocaine 1\%) infiltration at the shock wave site. Kathmandu Univ Med J 2009; 7:92-6.

3. Skolarikos A, Alivizatos G, de la Rosette J. Extracorporeal shock wave lithotripsy 25 years later: complications and their prevention. Eur Urol 2006;50:981-90.

4. Al-Ansari A, As-Sadiq K, Al-Said S, et al. Prognostic factors of success of extracorporeal shock wave lithotripsy (ESWL) in the treatment of renal stones. Int Urol Nephrol 2006;38:63-7.

5. Abdel-Khalek M, Sheir KZ, Mokhtar AA, et al. Prediction of success rate after extracorporeal shock wave lithotripsy of renal stones- a multivariate analysis model. Scand J Urol Nephrol 2004;38:161-7.

6. Abdel-Khalek M, Sheir K, Elsobky E, et al. Prognostic factors for extracorporeal shock-wave lithotripsy of ureteric stones--a multivariate analysis study. Scand J
UrolNephrol 2003;37:413-8.

7. Salman M, Al-Ansari AA, Talib RA, et al. Prediction of success of extracorporeal shock wave lithotripsy in the treatment of ureteric stones. Int Urol Nephrol. 2007;39:85-9.

8. Shrestha B, Baidya JL. Outcome of Extracorporeal Shock Wave Lithotripsy at B and B Hospital. J Nep Med Assoc 2010;49:38-42.

9. Lingeman JE, Newman D, Mertz JHO, et al. Extracorporeal shockwave lithotripsy: The Methodist hospital of Indiana Experience. J Urol 1986;135:1134-7.

10. Newman RC, Finlayson B. New developments in ESWL. AUA update series 1988;7:50.

11. Lalak NJ, Moussa SA, Smith G, et al. The Dornier compact Delta lithotriptor: the first 500 renal calculi. J Endourol 2002; 16: 3-7.

12. Chaussy C, Bergsdorf T. Extracorporeal shockwave lithotripsy for lower pole calculi smaller than one centimeter. Indian J Urol 2008;24:517-20.

13. Preminger GM, Tiselius HG, Assimos DG, et al. 2007 guideline for the management of ureteral calculi. J Urol 2007; 178:2418-34.

14. Delakas D, Karyotis I, Daskalopoulos G, et al. Independent predictors of failure of shockwave lithotripsy for ureteral stones employing a secondgeneration lithotripter. J Endourol 2003;17:201-5.

15. Wen CC, Nakada SY. Treatment selection and outcomes: renal calculi. Urol Clin North Am 2007;34: 409-19.

16. Ackermann DK, Fuhrimann R, Pfluger D, etal. Prognosis after extracorporeal shock wave lithotripsy of radiopaque renal calculi: a multivariate analysis. Eur Urol 1994; 25: 105-9.

17. Lingeman JE, Woods J, Toth PD. The role of lithotripsy and its side effects. J urol 1989;141:793-7. 